\title{
Malnutrition-modulated diabetes mellitus (MMDM): a state of review
}

\author{
Akadiri YESSOUFOU ${ }^{1,2}$, Jean-Marc ATĖGBO ${ }^{1,3^{*}}$, Kabirou MOUTAIROU ${ }^{1,2}$, K. L. \\ DRAMANE $^{1}$ and Naim Akhtar KHAN ${ }^{1}$ \\ ${ }^{1}$ University of Burgundy, Department of Physiology, UPRES EA 4163 "Lipids and Signalisation Cellular", \\ Faculty of Life Sciences, Dijon, France. \\ ${ }^{2}$ Laboratory of Cell Biology and Physiology, Department of Biochemistry and Cell Biology, Faculty of \\ Sciences and Techniques, University of Abomey-Calavi, Cotonou, Benin. \\ ${ }^{3}$ Department of Animal Physiology, Faculty of Sciences and Techniques, University of Abomey-Calavi, BP 526 \\ Cotonou, Benin. \\ *Corresponding author, E-mail: jmarcategbo@yahoo.fr
}

\begin{abstract}
Diabetes is a worldwide public health problem and is progressively increasing in Third World countries, particularly in African continent and Southern Asia due to low socio-economic standards. Since malnutrition and undernutrition with cassava consumption and cyanide intoxication have been thought to be the major cause of diabetes in tropical countries, WHO Expert Committee on Diabetes suggested, in its report, that the relationship between Malnutrition-Modulated Diabetes Mellitus (MMDM) and high cassava consumption should be clarified. Be that as it may, many recent studies have failed to establish a link between tropical diabetes and cassava malnutrition. In this paper, we shed light on MMDM in order to reach a consensus on its clinical, physiological and pathogenic features.
\end{abstract}

(C) 2008 International Formulae Group. All rights reserved.

Keywords: Tropical diabetes, cassava, immune disease, clinical features.

\section{INTRODUCTION}

For a long time, diabetes has been considered a disease of developed countries. However, in the past years, it has emerged as a worldwide public health problem, particularly in tropical countries (Monteiro et al., 1991; Rolfe et al., 1992; Mbanya et al., 2003). In 1997, about 127 million diabetic patients were recorded all over the world and, by 2010 , the number will have reached 221 million (Amos et al., 1997). In addition, it is believed that, in Africa, the prevalence of diabetes will be multiplied by a factor of 2 or 3 (Amos et al., 1997).

Although the classical criteria like age of diabetes onset, obesity symptoms, family history of diabetes, urinary ketosis and autoimmunity context allow to identify patients suffering from the major types of diabetes (Type I and Type II) in developed countries (Keen, 1986), a number of patients in tropical countries don't satisfy this traditional classification (Ahuja, 1965; West, 1980; Mohan and Alberti, 1992).

World Health Organisation (WHO) classification of diabetes distinguishes between insulin dependent diabetes mellitus (IDDM) termed Type I diabetes mellitus ( $\mathrm{T}$ 1DM), non-insulin dependent diabetes mellitus (NIDDM) termed Type II diabetes mellitus ( $\mathrm{T}$ 2DM) and malnutrition related diabetes mellitus (MRDM) (Alberti, 1993). In many cases, the classification is difficult because insulin requirements fluctuate greatly. The incidence of obesity in T 2DM patients is lower in Africa than in industrialized countries (Hjelm et al., 2003; Bazzano et al., 2005; Dagogo-Jack, 2006).

MRDM can be subdivided into proteindeficient diabetes mellitus (PDDM) and 
fibrocalculus pancreatic diabetes (FCPD). While FCPD pancreatitis manifests itself in pancreatic duct calculi, PDDM is related to the presence of ketosis-resistant hyperglycaemia (Ahren and Corrigan, 1985). As far as epidemiology is concerned, not much is known. However, it had been previously reported that $5.2 \%$ of the patients in Cuttack, India (Tripathy and Samal, 1993), $6.2 \%$ in Korea (Huh et al., 1992) and 6\% in Nigeria (Akanji, 1990) are suffering from this type of diabetes. Among patients with onset of diabetes by 30 years of age, $53 \%$ were diagnosed as MMDM, at Cuttack, India, (Tripathy and Samal, 1993), 36\% in Dhaka, Bangladesh (Azad-Khan et al., 1991). Nowadays, the term MRDM has been replaced by MMDM. Therefore, in this review, we will use the term MMDM instead of MRDM

The purpose of this article is to make a review of literature on tropical diabetes mellitus in order to reach a consensus on the exact clinical, physiological and etiopathological features of MalnutritionModulated Diabetes Mellitus (MMDM).

\section{FOOD HABITS}

Differences are found in the "dishes" consumed from country to country, region to region, locality to locality, even family to family (Kittler and Sucker, 2001). Although cassava roots are the most useful part of the crop, people in some regions eat the leaves too. The cassava root, however, cannot always be directly consumed. Many varieties in fact contain cyanogenetic compounds which release the highly toxic hydrogen cyanide and if these varieties, called bitter cassava, are to be used, they have to be detoxified. There are a number of ways of doing this. The most common one in rural areas is steeping, using large quantities of water. Grating, mixing and washing followed by drying will also eliminate hydrogen cyanide

There are three ways of eating cassava and the extend to which each is used depends on the individual country in question. The sweet varieties are eaten raw, boiled or fried. The bitter varieties are steeped first. The pasta, starch and flour made from the tubers is stable and can be sold and cassava floor is often mixed with wheat flour to make bread.
Among urban indigenous women in Fiji, the food frequency study revealed that cassava, bread and sugar were consumed daily as the main carbohydrate foods. The impact of dietary transition, coupled with dietary excess and physical inactivity, seem to be potential risk factor of diabetes (Lako and Nguyen, 2001)

\section{CLINICAL FEATURES}

The general clinical features of the patients suffering from MMDM in different parts of the world e.g. India, Bangladesh, Ethiopia, are identical. Acute symptoms are polyuria and polydipsia, whereas chronic symptoms are weakness, wasting, cramping abdominal pain and skin infections. MMDM patients are typically young at onset with low body mass index, require insulin treatment for glycemic control, have insulin resistance, and do not develop ketosis on withdrawal of insulin.

According to Samal et al., (2002), the clinical picture of MMDM is similar to that of $\mathrm{T}$ 1DM, but it develops upon a background of chronic malnutrition in childhood. Fortunately, in spite of severe hyperglycaemia, ketonuria never occurs. MMDM patients are extremely lean and require high doses of insulin-over 2.0 $\mathrm{U} / \mathrm{kg} /$ day for good glycemic control (Tripathy and Samal, 1997). Even when optimally controlled, these patients maintain their leanness. Infections of the skin and soft tissues and pulmonary tuberculosis are often seen. Micro- and macrovascular complications are rare, due to long-term follow-up. Ultrasonographic evaluation of the abdomen clearly differentiates MMDM from FCPD. Absence of ketonuria and ketosis, despite very severe hyperglycaemia in lean young subjects, is the most significant marker of MMDM.

\section{IS MMDM AN IMMUNE-MEDIATED DISEASE?}

WHO's revised classification in 1999 , based on the etiopathogenesis of the disease, identifies only two categories: T $1 \mathrm{DM}$ and $\mathrm{T}$ 2DM. T 1DM is a polygenic disorder with an autoimmune basis for disease development. The presence of autoantibodies to $\mathrm{T} 1 \mathrm{DM}$ autoantigens in clinical MMDM either identifies the slow-onset form of T 1DM or suggests autoimmunity different from that in 
T 1DM. MMDM could be considered Type 1b diabetes. Immunological studies carried out on MDDM patients in Cuttack (India), account for its inclusion in the category of Type $1 \mathrm{~b}$ diabetes. Hence, antibodies (Abs) to tyrosine pyrophosphatase (IA2-Abs), glutamate decarboxylase 65 (GAD65-Abs), and other minor markers like ICA12 Abs and tissue transglutaminase Abs (TTG-Abs) have been looked for. The autoantibody-negative PDDM patients were analyzed for HLA, showing that DR7-DQ9 is increased in this group compared to healthy controls, which suggests an autoimmune response to an unknown dietary autoantigen (Kanungo et al., 2002). These authors conclude that an autoimmune mechanism is involved in the etiology of MMDM. In addition, the presence of silent celiac disease seen with MMDM patients is significant. It is important to note that subclinical celiac disease exists with diabetes mellitus and must be taken into consideration in the diagnosis of MMDM (Deja et al., 2008; Remes-Troche et al., 2008; Salardi et al., 2008).

Pancreatic pathology is characterised by reduced size of the pancreas. In microscopical observations, acinar cells are normal in appearance and islets of Langerhans appear reduced in number, though normal in size, morphology and distribution of cell types. There is no evidence of inflammation or fibrosis (Tripathy and Samal, 1997). These findings are quite different from those in FCPD and in many respects from $T$ 1DM (Tripathy and Samal, 1997). Islet cell antibodies (ICA) were detected in 3 out of 30 patients (10\%) in Ethiopia (Abdul-Kadir et al., 1989), 11 out of $22(50 \%)$ in Korea (Huh et al., 1992) and only one case in Indonesia (Wiyono et al., 1989). Two out of 9 patients $(22 \%)$ in Cuttack were positive for ICA (Tripathy and Samal, 1997). GAD antibodies were positive in 9 out of 52 Cuttack patients (17\%) with MMDM compared with $2 \%$ in healthy controls. The frequency of positivity was not influenced by the duration of the disease.

As far as immuno-genetic studies on MMDM are concerned, there are only a few data available on this subject. Sanjeevi et al., (2002) have analyzed the HLA class II gene polymorphism in MMDM, which was previously referred to as PDDM in the 1985
WHO classification. In addition to HLA, a second susceptibility locus for T $1 \mathrm{DM}$ has been identified to lie in the major histocompatibility class III region. Both $\mathrm{T}$ 1DM and MMDM in Eastern Indians are associated with DR3-DQ2 but not DR4-DQ8. Wiyono et al., (1989) and Tripathy et al., (1993) have demonstrated that the presence of GAD 65 antibody and DR3-DQ2 positivity in MMDM patients identifies the underlying autoimmune mechanism in the etiology in Eastern India. In autoantibody-negative MMDM patients, an association with DR7DQ2 has been identified. The data obtained also indicate the possibility that MMDM can coexist with T 1DM in these patients and that malnutrition could be one of the reasons for the slower onset in T 1DM-prone individuals. The association DR7-DQ2 suggests that there is a different immunogenetic background to MMDM than to T 1DM.

Some recent studies evoked a genetic basis and SPINK-1 mutation in FCPD (Bhatia et al., 2002; Tandon and Garg, 2004). Schneider et al. (2002) have found in Bangladesh that the SPINK-1 N34S mutation increases the risk of several forms of pancreatic disease. SPINK-1 mutations appeared in 12 out of 22 patients $(54.55 \%)$ with FCPD, 3 out of 15 patients $(20 \%)$ with tropical calcific pancreatitis, 6 out of 43 patients $(13.95 \%)$ with T 2DM and 1 out of 76 $(1.32 \%)$ control subjects. These findings suggest that MMDM is immunogenetically different from T 1DM in Eastern India.

\section{ARE C-PEPTIDE LEVELS IMPLICATED?}

When MMDM is insulin-dependent with urinary ketosis and without insulin therapy, the C-peptide level is very low on fasting or after glucose ingestion (Mohan et al., 1985). But when MMDM is insulinrequiring, without urinary ketosis, the $\mathrm{C}$ peptide concentration is intermediary. In case of MMDM non insulin-dependent, in which oral treatment is favourable, the C-peptide level remains low but appreciable. It appears clearly that, therapeutically, MMDM can acquire the form of $\mathrm{T} 1 \mathrm{DM}$ or the form of $\mathrm{T}$ $2 \mathrm{DM}$ or an intermediary form which is insulin-requiring diabetes.

Nonetheless, this kind of diabetes has been considered to be the result of insulinopenia, low insulin reserve and 
diminished sensitivity to insulin. All reports are unanimous on low levels of insulin and Cpeptide during fasting and in response to glucose or glucagons (Cheng et al., 1992; Iwasaki et al., 1994). Values are substantially lower than in normal, but higher than those in $\mathrm{T}$ 1DM. These findings suggest the persistence of some residual $\beta$-cell function for many years after the onset of the pathology.

\section{IS CASSAVA IMPLICATED?}

Cassava, commonly known as tapioca or manihot, is widely cultivated in more than 80 tropical countries and often consumed as a staple food. It provides a cheap source of high carbohydrates with low protein contents (Table 1). Cassava is known to contain cyanogenic glycosides, linamarin and lotaustralin (Nartey, 1968). It still remains unclear whether MMDM should be considered a distinct clinical entity, though many epidemiological studies have failed to establish unequivocally the correlationship between its prevalence and cassava consumption or protein malnutrition (AbuBakare et al., 1986; Teuscher et al., 1987; Akanji, 1990; Akanji et al., 1990; Gautier et al., 2001).

The National Diabetes Data Group (1979) and the WHO Expert Committee on diabetes (1980) acknowledged the malnutrition as a putative aetiological factor in the pathogenesis of certain forms of diabetes. Several investigators have observed in patients with MMDM, a history of malnutrition during childhood (Nwokolo 1980; Abu-Bakare et al., 1986; Djrolo et al., 1998). These patients were from the poorest socio-economic strata of the rural sector of Central Africa. Dietary calculations revealed low intake of total calories $(62 \%)$, carbohydrates $(72 \%)$, proteins $(56 \%)$ and fats $(53 \%)$ as compared with recommended allowances before the onset of diabetes (Huh et al., 1992). Clinical (Smith et al., 1975; Balasse and Fery 1992) and experimental studies (Okitotonda et al., 1987; 1988) have shown that protein malnutrition and fasting are associated with the alteration of glucose homeostasis (Figure 1) (Yessoufou et al., 2006). Moreover, the diet toxic agents like cassava derivatives, mostly carbohydrate-rich diet, have been evoked in the genesis of MMDM (McMillan and Geevarghese 1979; McMillan, 1986). Indeed, high consumption of cassava or its derivatives is generally correlated with high prevalence of MMDM (McMillan and Geevarghese 1979; Nwokolo and Oli, 1980). In contrast, Swai et al., (1992) have reported that high dietary cyanide exposure was not found to have had a significant effect on the prevalence of diabetes in an undernourished population in two rural communities in Tanzania. Cassava consumption is thus highly unlikely to be a major etiological factor in so-called MMDM, at least in East Africa. Teuscher et al., (1987) have found no diabetes incidence in a population in West Africa who had high consumption of cassava. Similarly, Mathangi et al., (2000) have not observed any diabetes in rats fed, for one year, on a cassava richdiet. There were transient changes in serum insulin and lipase levels, but the significance of these findings are not clear. There was no histopathological evidence of either acute or chronic pancreatitis, but there were changes of toxic hepatitis in the liver. Chronic cassava ingestion up to a year does not lead to either diabetes or chronic pancreatitis in the rat model. These results are in accordance with those of Soto-Blanco et al., (2001) who observed that chronic cyanide exposure did not promote diabetogenic effects in rats, swine or goats, suggesting that cyanide is not responsible for MMDM in humans.

Nevertheless, the high consumption of tapioca (cassava) seems to increase diabetic risk with a factor of 3.2 in rats, and in the people of Borno state in Nigeria (Chibuzo and Ajayi, 2000). Finally, it appears that a high dietary uptake of cassava is "diabetesgenerating" because cassava is poor in protein (Rao 1983, 1988; Akanji 1993). Cassava contains the cyanogenic glycosides which generate cyanhydric acid which is toxic to the pancreas. The detoxification of these compounds needs sulphur amino-acids. Cassava consumption without sufficient protein nutrition leads to massive cyanhydric accumulation which induces pancreatic calcification and then diabetes (Ranivontsoarivony et al., 2001; Yessoufou et al., 2006). 
Table 1: Composition of standard and cassava-based diets ( $\mathrm{g} / \mathrm{kg}$ of diet)

\begin{tabular}{|c|c|c|c|c|c|}
\hline \multirow[b]{2}{*}{ compositions } & \multirow[t]{2}{*}{ Standard diet } & \multicolumn{4}{|c|}{ Cyanide-free Cassava (CFC) based diets } \\
\hline & & Diet A & Diet B & Diet $\mathrm{C}$ & Diet D \\
\hline Starch & 587 & 85 & 85 & 85 & 85 \\
\hline Tapioca (cassava) \# & & 502 & 505 & 503.1 & 500.1 \\
\hline Potassium cyanide $\$$ & & & & 1.9 & 1.9 \\
\hline DL-Methionine & 3 & 3 & & & 3 \\
\hline Casein & 200 & 200 & 200 & 200 & 200 \\
\hline sucrose & 50 & 50 & 50 & 50 & 50 \\
\hline cellulose & 50 & 50 & 50 & 50 & 50 \\
\hline mineral mix ${ }^{\mu}$ & 40 & 40 & 40 & 40 & 40 \\
\hline vitamin mix ${ }^{\mu}$ & 20 & 20 & 20 & 20 & 20 \\
\hline oil Isio-4 & 50 & 50 & 50 & 50 & 50 \\
\hline Total & 1000 & 1000 & 1000 & 1000 & 1000 \\
\hline
\end{tabular}

Values are in $(\mathrm{g})$ per $(\mathrm{kg})$ of the diet.

$\$$ Cyanide (Prolabo, Normapur®, Paris, France) in sub-lethal dose according to Akanji and Famuyiwa (1993).

$\mu$ Composition, according to Tribulot et al. (2001).

\# Cassavas were certified cyanide-free by International Institute of Tropical Agriculture (Cotonou, Benin). Total oil represented $5 \%$ of the diet. In each diet group, a total of 5 female Wistar rats were rendered diabetic by five low intraperitoneal (ip) injections of streptozotocin $(20 \mathrm{mg} / \mathrm{kg}$ body weight) in $0.1 \mathrm{M}$ citrate buffer, $\mathrm{pH} 4.5$, from day 1 to day 5. Glycaemia was determined on day 8 and day 12 .

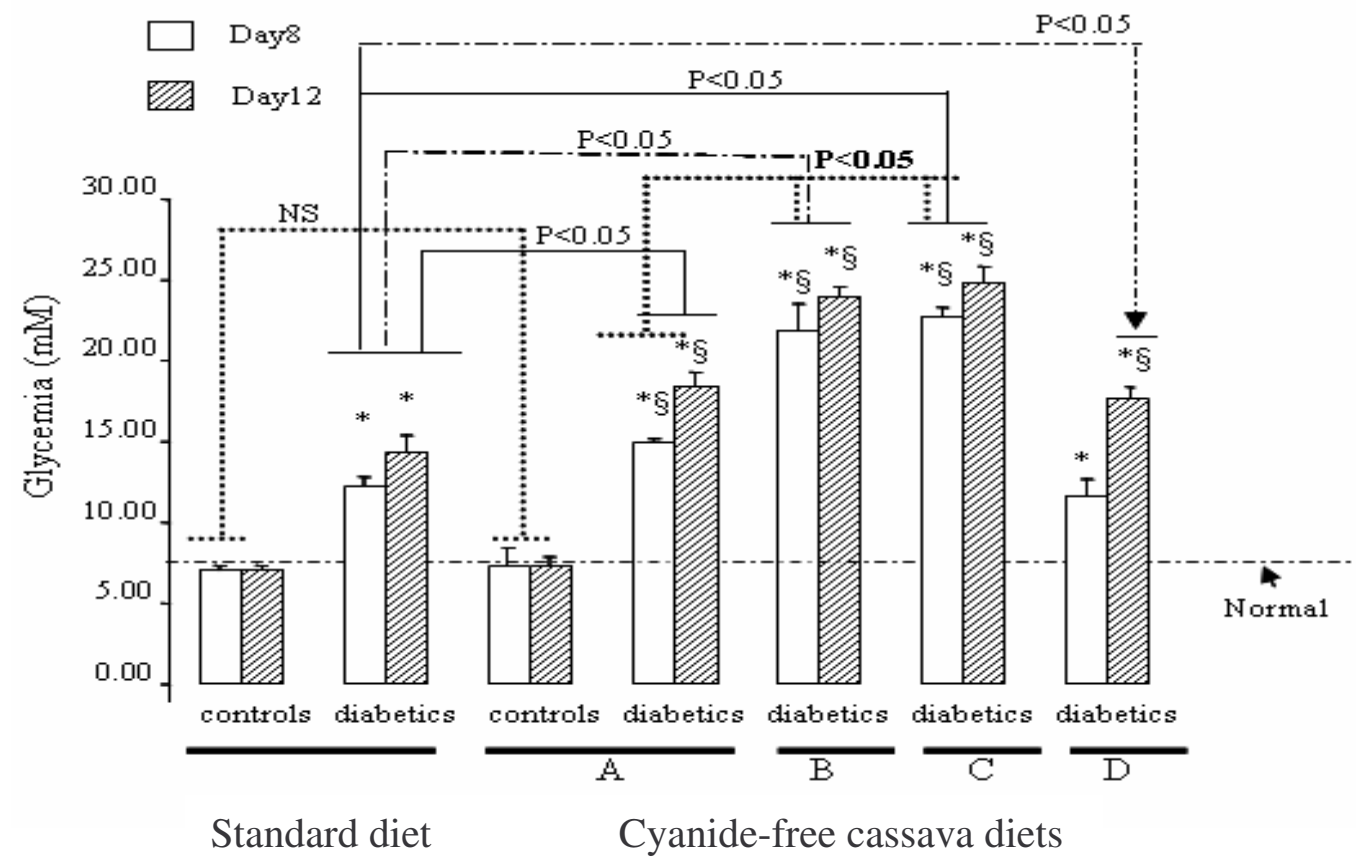

Figure 1: Glycaemia on day8 and day12 in wistar rats was determined by One Touch II ${ }^{\circledR}$ Glucometer (LifeScan, Johnson and Johnson, USA). Values are mean \pm SD. Significant differences between STZ-induced diabetic rats and their corresponding controls are indicated as follows: ${ }^{*} \mathrm{p}<0.05$. Significant difference between Experimental diet and Standard diet is indicated as follows: $\$ p<0.05$. Day8 and day 12 correspond respectively to the $8^{\text {th }}$ and $12^{\text {th }}$ day of the first injection of streptozotocin. (Yessoufou et al., 2006). 
We have also recently observed that cassava consumption did not induce diabetes but increased diabetes potency in rats (Yessoufou et al., 2006). To put it in nutshell, cassava consumption appears as a diabetesaggravating factor.

\section{COMPLICATIONS}

Peripheral neuropathy, frequent during MMDM (Djrolo et al., 1998; Mohan et al., 1985), is related to the amyotrophic and functional impotency which stimulates neuropathy in Beninese subjects (Djrolo et al., 1998). In Ivory Coast, $70 \%$ of diabetic patients catch neuropathy (Lokrou et al., 1987). The particular frequency of neuropathy is probably related to nutritional factors (Djrolo et al., 1998). The limb infection is particularly important, serious and frequent (Abbas et al., 2001). Some authors have pointed out that member infection is specifically tropical, in contrast to observations in the West (Gill et al., 1998). Degenerative complications could be observed in MMDM with lower prevalence than that observed in T 2DM (Mohan et al., 1985). Diabetic retinopathy may be prevalent (Mohan et al., 1985; 1987); but, macroangiopathy also exists (CorreaGiannella and Vieira, 2008; Fujii et al., 2008; Mastej and Adamiec, 2008).

\section{CONCLUSION}

It is well recognized that some patients with diabetes mellitus in tropical regions and in some developing countries present other forms of T 1DM and T 2DM, different from those of Western world and developed countries. In 1985, the WHO Study Group acknowledged this by recognizing a third class of diabetes, designated as MRDM and subdivided into PDDM and FCPD. Since then, more information has been obtained about diabetes in tropical areas and should form the basis for further investigations into aetiological, epidemiological and clinical factors of such diabetes. Whilst it appears that malnutrition may influence the expression of several types of diabetes, the evidence that diabetes can be caused by malnutrition or protein deficiency per se is not convincing. Therefore, it is recommended that the class "Malnutrition-related diabetes mellitus
(MRDM)" be deleted. However, some experiments are required.

This review reports that the form of tropical diabetes formerly named MRDM is exceptional in tropical Africa, as previously observed in other countries. The rarity of MRDM cases and the lack of systematic association between malnutrition and this form of diabetes lead to reconsider the classification regarding diabetes in tropical regions. Following the International Workshop of Cuttack, India, and the Report of WHO Consultation (Geneva 1999), the delegates of several developing countries recommended replacing the term MRDM by MMDM. FCPD, an uncommon form in West Africa, but prevalent in other tropical populations, was considered a separate form. Moreover, there are many factors, such as low body weight, that are not well understood in subjects with T 2DM; hence, the need for further research to advance our knowledge on the topic.

\section{ACKNOWLEDGEMENTS}

We express ours sincere thanks to the French Embassy at Cotonou, Benin, and the Office of Scholarship Programme of IDB that granted a scholarship to one of the authors (A. Yessoufou). Thanks are due to the Ministry of Higher Education, Republic of Benin, which granted a scholarship to JM Atègbo.

\section{REFERENCES}

Abbas ZG, Lutale J, Gill GV, Archibald LK. 2001. Tropical diabetic hand syndrome: risk factors in an adult diabetes population. Int. J. Infect. Dis., 5: 19-23.

Abdul-Kadir J, Worku Y, Schreuder GMT, D'Amaro J, de Vries RRP, Ottenhoff THM. 1989. HLA-DR-DQ antigens in malnutrition-related diabetes mellitus in Ethiopians a clue to its aetiology. Tissue Antigens, 34: 284-289.

Abu-Bakare A, Taylor R, Gill GV, Alberti KG. 1986. Tropical or malnutritionrelated diabetes: a real syndrome? Lancet, 1: 1135-1138.

Ahren B, Corrigan CB. 1985. Intermittent need for insulin in a subgroup of diabetic patients in Tanzania. Diabetic Med., 2: 262-264.

Ahuja MMS. 1965. Ketosis-resistant young diabetics. Lancet, VI: 1224-1225. 
Akanji AO, Adeyefa I, Charles-Davies M, Osotimehin BO. 1990. Plasma glucose and thiocyanate responses to different mixed cassava meals in non-diabetic Nigerians. Eur. J. Clin. Nutr., 44: 71-77.

Akanji AO, Famuyiwa OO. 1993. The effect of chronic cassava consumption, cyanide intoxication and protein malnutrition on glucose tolerance in growing rats. $\mathrm{Br} . \mathrm{J}$. Nutr., 69: 276-279.

Akanji AO. 1990. Malnutrition-related diabetes mellitus in young adult diabetic patients attending a Nigerian diabetic clinic. Am. J. Tropical. Med. Hygiene, 93: 35-38.

Alberti KGMM. 1993. Problems related to definitions and epidemiology of Type 2 (non-insulin-dependent) diabetes mellitus: studies throughout the world. Diabetologia, 6: 978-984.

Amos AF, McCarty DJ, Zimmet P. 1997. The rising global burden of diabetes and its complications: estimates and projections to the year 2010. Diabet. Med., 14: 81-85.

Azad-Khan AK, Banik NG, Mahtab H. 1991. Malnutrition-related diabetes mellitus in Bangladesh. In Diabetes Excerpta Medica, ICS 1000, Rifkin H, Colwel JA, Taylor SI (eds). Elsevier: Amsterdam; 944-949.

Balasse EO, Fery F. 1992. Physiopathologie du diabète de famine. In Journée de Diabétologie Hôtel Dieu. Flammarion Médecine Science : Paris ; 87-99.

Bazzano LA, Serdula M, Liu S. 2005. Prevention of type 2 diabetes by diet and lifestyle modification. J. Am. Coll. Nutr., 24: 310-319.

Bhatia E, Choudhuri G, Sikora SS, Landt O, Kage A, Becker M, Witt H. 2002. Tropical calcific pancreatitis: strong association with SPINK1 trypsin inhibitor mutations. Gastroenterology, 123: 10201025.

Cheng HM, Jap TS, Lee KT, Kwok CF, Ho LT. 1992. Arginine induced insulin release in patients with newly onset noninsulin-dependent diabetes mellitus. Zhonghua Yi Xue Za Zhi (Taipei), 50: 184-188.

Chibuzo EC, Ajayi OA. 2000. Effect of Wainan Rogo on body weight and plasma glucose in Wistar rats. Nutr. Health, 14: 133-140.
Corrêa-Giannella ML, Vieira SM. 2008. Genetic susceptibility to microangiopathy development in Type 1 diabetes mellitus. Arq Bras Endocrinol. Metabol., 52: 375386.

Dagogo-Jack S. 2005. Primary prevention of cardiovascular disease in pre-diabetes: the glass is half full and half empty. Diabetes Care, 28 : 971-972.

Deja G, Myrda A, Jarosz-Chobot P, Siekiera U. 2008. The assessment of autoimmunological status and prevalence of different forms of celiac disease among children with type 1 diabetes mellitus and celiac disease. Mediators Inflamm., 28: 59-89.

Djrolo F, Houngbe H, Avode G, Attolou V, Addra B, Kodjoh N, Avimadje M, Monteiro B, Zohoun TH, Hountondji A. 1998. Le diabète lié à la malnutrition (diabète tropical): A propos d'un cas observé en Médecine interne à Cotonou. Méd. Afrique Noire, 45: 538-542.

Fujii T, Onimaru M, Yonemitsu Y, Kuwano H, Sueishi K. 2008. Statins restore ischemic limb blood flow in diabetic microangiopathy via eNOS/NO upregulation but not via PDGF-BB expression. Am $J$ Physiol Heart Circ. Physiol. (Epub ahead of print).

Gautier JF, Sobngwi E, Vexiau P. 2001. How to treat and manage the black diabetic patient. Journ Annu Diabetol Hotel Dieu., 165-178.

Gill GV, Famuyiwa OO, Rolfe M, Archibald LK. 1998. Serious hand sepsis and diabetes mellitus: specific tropical syndrome with western counterparts. Diabet. Med., 15: 858-862.

Hjelm K, Mufunda E, Nambozi G, Kemp J. 2003. Preparing nurses to face the pandemic of diabetes mellitus: a literature review. J. Adv. Nurs., 41: 424-434.

Huh KB, Lee HC, Kim HM, Cho YW, Kim YL, Lee KW, Lee EJ, Lim SK, Kim DH, Yoon JW. 1992. Immunogenetic and nutritional profile in insulin using youth onset diabetic in Korea. Diabet. Res. Clin. Prat., 16: 63-70.

Iwasaki Y, Kondo K, Hasegawa H, Oiso Y. 1994. C-peptide response to glucagon in type 2 diabetes mellitus: a comparison with oral glucose tolerance test. Diabetes Res., 25: 129-137. 
Kanungo A, Samal KC, Sanjeevi CB. 2002. Molecular mechanisms involved in the etiopathogenesis of malnutritionmodulated diabetes mellitus. Ann. N. Y. Acad. Sci., 958: 138-143.

Keen H. 1986. Diagnosis and classification of diabetes mellitus. World Book Diabet. Pract., 2: 8-15.

Kittler PG, Sucker KP. 2001. Food and culture $\left(3^{\text {rd }}\right.$ edn $)$. Stamford, CT: Wadsworth.

Lako JV, Nguyen VC. 2001. Dietary patterns and risk factors of diabetes mellitus among urban indigenous women in Fiji. Asia Pac. J. Clin. Nutr., 10: 188-193.

Lokrou A, Toutou T, Ouedraogo Y, Groga Bada N, Koutouan A, Diallo A. 1987. Complication du diabète sucré en milieu hospitalier en Côte d'Ivoire. Med. Afr. Noire, 34: 593-602.

Mastej K, Adamiec R. 2008. Neutrophil surface expression of CD11b and CD62L in diabetic microangiopathy. Acta Diabetol., (Epub ahead of print).

Mathangi DC, Deepa R, Mohan V, Govindarajan M, Namasivayam A. 2000. Long-term ingestion of cassava (tapioca) does not produce diabetes or pancreatitis in the rat model. Int. J. Pancreatol., 27: 203-208.

Mbanya JC, Mfopou JK, Sobngwi E, Mbanya DN, Ngogang JY; Cameroon Study. 2003 Metabolic and hormonal effects of five common African diets eaten as mixed meals: the Cameroon Study. Eur. J. Clin. Nutr., 57: 580-585.

McMillan DE, Geevarghese PJ. 1979. Dietary cyanide and tropical malnutrition diabetes. Diabetes Care, 2: 202-208.

McMillan DE. 1986. Tropical malnutrition diabetes. Diabetologia, 29: 127-128.

Mohan R, Rajendran K, Mohan V, Ramachandran A, Viswanathan $M$, Konher EMM. 1985. Retinopathy in tropical pancreatic diabetes. Arch. Opthalmol., 103: 1487-1489.

Mohan V, Mohan R, Suscheela L, Bharani G, Mahajan VK, Ramachandran A, Viswanathan M, Kohner EM. 1985. Tropical pancreatic diabetes in South India: heterogeneity in clinical and biochemical profile. Diabetologia, 28: 229-232.
Mohan R, Rajendran B, Mohan V, Ramachandran A, Viswanathan M, Konher EM. 1987. Retinopathy in tropical pancreatic diabetes. Diabetes Care, 10: 532-533.

Mohan V, Alberti KGMM. 1992. Diabetes in the tropics. In Textbook of Diabetes Mellitus, Alberti KGMM, de Fronzo RA, Keen H, Zimmel P (eds). John Wiley \& Sons Ltd; 177-196.

Monteiro B, Gninafon M, Amoussou KJ. 1991. Contribution à l'étude épidémiologique du diabète sucré de l'adulte au CNHU de Cotonou. Méd. Afrique Noire, 38 : 263-269.

Nartey E. 1968. Studies on cassava manihot utilissima Pohl. Cyanogenesis: the biochemistry of linamarin and lotaustrolin in etiolated seeding. Phytochemistry, 7: 1307-1312.

National Diabetes Data Group (NDDG). 1979. Classification and diagnosis of diabetes mellitus and other categories of glucose intolerance. Diabetes, 28: 1039-1057.

Nwokolo C, Oli J. 1980. Pathogenesis of juvenile Tropical. Pancreatitis syndrome. Lancet, III: 456-459.

Okitotonda W, Brichard SM, Henguin JC. 1987. Repercussions of chronic proteincalorie malnutrition on glucose homeostasis in the rat. Diabetologia, 50: 946-951.

Okitotonda W, Brichard SM, Pottier AM, Henguin JC. 1988. Influence of low and high-protein diets on glucose homeostasis in the rat. Br. J. Nutr., 60: 509-516.

Rao RH. 1983. The role of under-nutrition in the pathogenesis of diabetes mellitus. Diabetes Care, 7: 595- 601.

Rao RH. 1988. Diabetes in the undernourished: coincidence or consequence? Endocrine Rev., 9: 67-87.

Ranivontsoarivony M, Noronavalona A, Raharison N, Rajaona HR. 2001. Is manioc a diabetogenic factor? Apropos of a case of diabetes mellitus with a large consumption of crude manioc. Bull Soc Pathol. Exot., 94: 312-314.

Remes-Troche JM, Rios-Vaca A, RamírezIglesias MT, Rubio-Tapia A, AndradeZarate V, Rodríguez-Vallejo F, LópezMaldonado F, Gomez-Perez FJ, Uscanga LF. 2008. High prevalence of celiac disease in Mexican Mestizo adults with 
type 1 diabetes mellitus. J. Clin. Gastroenterol., 42: 460-465.

Rolfe M, Tang CM, Walker RW, Bassey E, George M. 1992. Diabetes mellitus in Gambia, West Africa. Diabet. Med., 9: 484-488.

Salardi S, Volta U, Zucchini S, Fiorini E, Maltoni G, Vaira B, Cicognani A 2008. Prevalence of celiac disease in children with type 1 diabetes mellitus increased in the mid-1990s: an 18-year longitudinal study based on anti-endomysial antibodies. J. Pediatr. Gastroenterol. Nutr., 46: 612-614.

Samal KC, Kanungo A, Sanjeevi CB. 2002. Clinicoepidemiological and biochemical profile of malnutrition-modulated diabetes mellitus. Ann. N. Y. Acad. Sci., 958: 131-137.

Sanjeevi CB, Kanungo A, Samal KC. 2002. Immunogenetic studies on malnutritionmodulated diabetes mellitus. Ann. N. Y. Acad. Sci., 958: 144-147.

Schneider A, Suman A, Rossi L, Barmada MM, Beglinger C, Parvin S, Sattar S, Ali L, Khan AK, Gyr N, Whitcomb DC. 2002. SPINK1/PSTI mutations are associated with tropical pancreatitis and type II diabetes mellitus in Bangladesh. Gastroenterology, 123: 1026-1030.

Smith SR, Edgar PJ, Pozefsky T, Chhetri MK, Prout TE. 1975. Insulin secretion and glucose tolerance in adults with proteincalorie malnutrition. Metabolism, 24: 1073-1084.

Soto-Blanco B, Sousa AB, Manzano H, Guerra JL, Górniak SL. 2001. Does prolonged cyanide exposure have a diabetogenic effect? Vet. Hum. Toxicol., 43: 106-108.

Swai AB, Mclarty DG, Mtinangi BL, Tatala $\mathrm{S}$, Kitange HM, Mlingi N, Rosling $\mathrm{H}$,
Howlett WP, Brubaker GR, Alberti KG. 1992. Diabetes is not caused by cassava toxicity. A study in a Tanzanian community. Diabetes Care, 15: $1385-$ 1387.

Tandon RK, Garg PK. 2004. Tropical pancreatitis. Digestive Disease, 22: 258266.

Teuscher T, Baillod P, Rosman JB, Teuscher A. 1987. Absence of diabetes in a rural west Africa population with a high carbohydrate cassava diet. Lancet, IV: 765-768.

Tripathy BB, Samal KC. 1997. Overview and consensus statement on diabetes in tropical areas. Diabetes Metabolism Rev., 13: 63-67.

Tripathy BB, Samal KC. 1993. Protein deficient diabetes mellitus (PDDM) in India. Int. J. Diabetes Dev. Countries, 13: 3-13.

West KM. 1980. Secondary diabetes: the spectrum of the diabetic syndrome. In Diabetes in the Tropic. Raven Press; 249255.

WHO Expert Committee on diabetes mellitus. 1980. Second report. WHO Technical Report; Series 646, Geneva.

WHO Study Group on diabetes mellitus. 1985. Report of a WHO Study Group. Tech. Rep. Ser., 727: 20-25.

Wiyono P, Morimotto Y, Taniguchi H. 1989. The presence of islet cell antibodies in malnutrition-related diabetes mellitus. Diabetes Rec. Clin. Pract., 6: 75-78.

Yessoufou A, Atègbo JM, Girard A, Prost J, Dramane KL, Moutairou K, Hichami A, Khan NA. 2006. Cassava-enriched diet is not diabetogenic rather it aggravates diabetes in rats. Fundam. Clin. Pharmacol., 20: 579-586. 